\title{
Preclinical safety evaluation of chimeric antigen receptor-modified T cells against CD19 in NSG mice
}

\author{
Hairuo Wen ${ }^{1 \#}, Z_{\text {he }} \mathrm{Qu}^{1 \#}$, Yujing Yan ${ }^{1,2}$, Chengfei $\mathrm{Pu}^{3}$, Chao Wang ${ }^{1}$, Hua Jiang ${ }^{1}$, Tiantian Hou ${ }^{1}$, Yan Huo ${ }^{1}$ \\ ${ }^{1}$ Key Laboratory of Beijing for Safety Evaluation of Drugs, National Center for Safety Evaluation of Drugs, National Institutes for Food and Drug \\ Control, Beijing 100176, China; ${ }^{2}$ School of Pharmaceutical Sciences, Sun Yat-sen University, Guangzhou 510006, China; ${ }^{3}$ Innovative Cellular \\ Therapeutics Co., Ltd., Shanghai 201203, China \\ Contributions: (I) Conception and design: H Wen, C Pu, T Hou, Y Huo; (II) Administrative support: C Pu, Y Huo; (III) Provision of study materials: \\ C Pu; (IV) Collection and assembly of data: H Wen, Z Qu, Y Yan, C Wang, H Jiang; (V) Data analysis and interpretation: H Wen, Z Qu, Y Yan; (VI) \\ Manuscript writing: All authors; (VII) Final approval of manuscript: All authors. \\ \#These authors contributed equally to this work. \\ Correspondence to: Yan Huo, PhD. Professor, National Center for Safety Evaluation of Drugs, National Institutes for Food and Drug Control, Beijing \\ 100176, China. Email: yanhuo_nifdc@163.com.
}

Background: With the increase of chimeric antigen receptor-modified T (CAR-T) cell therapy, serious complications initiated by CAR-T cells have garnered wide attention. We have previously developed a

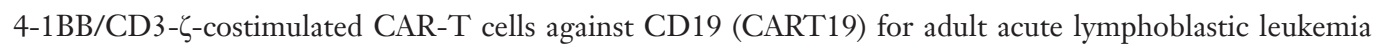
(ALL). In this study, a preclinical safety assessment of CART19 was performed on NSG mice, to evaluate the preclinical toxicity along with its efficacy and tissue distribution.

Methods: A total of 120 NSG mice were used for a combined pharmacodynamics and toxicity study for 56 days. Ninety-six mice of which were single dosed with Raji-Luc $\left(5 \times 10^{5}\right.$ per animal, i.p.) and different concentrations of CART19 $\left(0.2 \times 10^{7}, 0.6 \times 10^{7}\right.$ and $1.8 \times 10^{7}$ per animal, i.v.), while the rest were assigned to the Untreated group. Optical intensity of Raji-Luc in mice, clinical symptoms, body mass, hematological analysis, humanized cytokine, lymphocyte subset counting, necropsy and histopathological examinations were performed. In addition, a single dose of $0.6 \times 10^{7}$ CART19 was intravenously administered to 48 NSG mice, and the distribution of CART19 in different tissues was analyzed using quantitative PCR.

Results: CART19 is widely distributed in organs well-perfused with blood, including the lungs, blood, bone marrow, liver and spleen. Significant proliferation of CART19 was also found in the blood by through recognition using humanized $\mathrm{CD}^{+}$for $\mathrm{T}$ lymphocytes. The survival rate and leukemia related clinical symptoms in mice administered CART19 were markedly ameliorated, and the proliferation of Raji cells in mice was effectively inhibited. However, CART19 had no obvious effects on either the mean body mass or the blood cell counts, and no cytokine release syndrome and graft versus host disease were observed.

Conclusions: NSG mice given CART19 treatment demonstrated a longer survival period without significant immunotoxicity, suggesting encouraging clinical prospects for CART19 in patients with R/R ALL. Our study shed light on evaluation and supervision strategies for CAR-T products for the treatment of hematological diseases or leukemia.

Keywords: chimeric antigen receptor T cell (CAR-T cell); safety evaluation; biodistribution; toxicity; cytokine release syndrome (CRS); NSG mice

Submitted Aug 09, 2019. Accepted for publication Nov 14, 2019.

doi: $10.21037 /$ atm.2019.12.03

View this article at: http://dx.doi.org/10.21037/atm.2019.12.03 


\section{Introduction}

Radiotherapy, chemotherapy, surgery and hematopoietic stem cell transplantation as major means of cancer treatment have effectively prolonged the lifetimes of some patients; however, there remains an enormous challenge for patients with relapsed/refractory $(\mathrm{R} / \mathrm{R})$ tumor and those have developed resistance (1). The emergence of chimeric antigen receptor-modified $\mathrm{T}$ (CAR-T) cell therapy brought us novel strategies for fighting cancer. CAR-expressing $\mathrm{T}$ cells recognize a variety of monoclonal antibody-specific antigens on cell surfaces, such as polysaccharide proteins and glycolipids, and are therefore able to attack tumor cells by activating intracellular signals of corresponding antigens (2). CD19 antigen is highly expressed on the surfaces of B lymphocytes and their progenitor cells, as well as on tumor cells derived from B lymphocytes, including most lymphomas and lymphocytic leukemias (3). Therefore, CD19 antigen has become the most common target for CAR-T products for $\mathrm{R} / \mathrm{R}$ acute lymphoblastic leukemia (ALL) in children and adults, and has demonstrated impressive efficacy in patients with B cell malignancies (4-6). Yescarta (axicabtagene ciloleucel) (7) and Kymriah (tisagenlecleucel) (8), as two anti-CD19 CAR-T cell therapies, have been approved by FDA for clinical secondline treatment in 2017 successively, further increasing the enthusiasm of the scientific community for the development of CAR-T.

In addition to its significant curative effect, serious complications triggered by CAR-T cell therapy have garnered wide attention. Cytokine release syndrome (CRS, also known as cytokine storms), off-target tumor effects and neurotoxicity are the major risks of CAR-T cell therapy (9-11). For instance, severe CRS has been reported in patients infused with Kymriah, and symptoms such as hyperthermia, flu-like symptoms, severe infection, hypotension, acute kidney injury and hypoxia have been observed (8). As CD19 is ubiquitously expressed in all B lymphocytes, Kymriah is also targeted at normal B lymphocytes and subsequently increases the risk of infection due to B cell hypoplasia (8).

Therefore, it is crucial to weigh the benefit of antitumor efficacy and its side effects for patients during the development of CAR-T therapy. Preclinical safety evaluations in animal models cannot be omitted (12), and tumor-bearing mice with reconstituted human cell immune systems have become a popular model for anti-tumor activity evaluation of CAR-T. For example, both Yescarta and Kymriah adopted mice with reconstituted human cell immune systems in their toxicity and biodistribution studies $(7,8)$. However, the feasibility of immunodeficiency mouse models is under debate. Due to their lack of a host immune system, CAR-Ts are incapable of simulating the cascade reaction caused by CRS in these immunodeficient mice as occurs in patients, and interactions among CAR-T cells and other immune cells/tissue are also unable to be detected in these models, in addition to the on-target, off-tumor effects. However, what cannot be ignored is that they are currently the optimum preclinical research system for predicting neurotoxicity, graft versus host disease (GvHD), effects of CAR-T to local tissues, and the macrophage activation syndrome (MAS) (13). Along with the choice of animal models, we are facing another challenge in shaping feasible toxicological study schemes to capture the characteristics of CAR-T products. In spite of these challenges, the desired safety evaluation strategies for CAR-T products are still under exploration, and the biodistribution and immunotoxicity evaluations remain indispensable (14).

We have previously developed a 4-1BB/CD3- $\zeta-$ costimulated CAR-T cells against CD19 (CART19) (hereby referred as CART19) for adult ALL, which has been demonstrated as a potent antileukemia therapy for Chinese R/R ALL (15). In another clinical trial in which 92 patients were enrolled, patients who received CART19 showed significantly higher complete remission rates and fewer inhibitory effects on neutrophils and platelet counts, compared with the chemotherapy group (16). Herein, a comprehensive preclinical safety assessment of CART19 was performed using NOD-Prkdi $c^{\text {scid }} I L 2 r g^{t m 1} / \mathrm{Bcgen}$ (NSG) mice, including single-dose efficacy/toxicity and tissue distribution studies. This study will provide valuable information regarding the safety evaluation of CAR-T products for the treatment of hematological diseases and leukemia.

\section{Methods}

\section{Animals}

Six-week-old specific pathogen free (SPF) NSG mice were purchased from Beijing Biocytogen Co., Ltd. [Beijing, China; Animal Certificate No: SCXK (SU) 2016-0004]. The mice were housed in individually ventilated cages in a barrier system under conditions of $20-26{ }^{\circ} \mathrm{C}, 40-70 \%$ relative humidity, a 12 -hour light-dark cycle, and a cage air exchange of over 50 times per hour. Animals had ad libitum access to certified rodent diet, and sterilized municipal tap water was given ad libitum via water bottles. Before the 
study was conducted, mice were quarantined for 5 days.

\section{Cells}

CART19 was constructed as previously described (15). Both CART19 and freezing buffer containing electrolytes, human serum albumin, glucoside 40 and dimethyl sulfoxide were provided by Innovative Cellular Therapeutics Co., Ltd., Shanghai, China. CART19 cells were preserved at $-120^{\circ} \mathrm{C}$, while the freezing buffer was stored at $2-8{ }^{\circ} \mathrm{C}$ before use.

The Raji-Luc cell line for tumor xenografting was provided by Professor Weijin Huang at the National Institutes for Food and Drug Control. It was generated by stably infusing human Burkitt's lymphoma cell line Raji cells with firefly luciferase as a reporter (17). Raji-Luc cells were recovered and cultured using RPMI culture medium with $10 \%$ fetal bovine serum (FBS) and $1 \%$ penicillinstreptomycin solution in an incubator $\left(37^{\circ} \mathrm{C}, 5 \% \mathrm{CO}_{2}\right)$ and cells were adjusted to $2.5 \times 10^{6}$ cells $/ \mathrm{mL}$ using $0.9 \% \mathrm{NaCl}$ before use.

\section{Pharmacodynamics and toxicity study}

A total of 120 mice were used for a combined pharmacodynamics and toxicity study (Table 1), in which 48 males and 48 females were intravenously dosed with RajiLuc cells $\left(5 \times 10^{5}\right.$ cells per animal) for tumor xenografting, and the rest of animals (12 males and 12 females) were assigned to the Untreated group. Seventy-two hours after the injection of Raji-Luc cells, $3 \mathrm{mg}$ of d-luciferin ( $\mathrm{J} \& \mathrm{~K}$ Scientific, $30 \mathrm{mg} / \mathrm{mL}$ dissolved in $9 \mathrm{mg} / \mathrm{mL}$ $\mathrm{NaHCO}_{3}, 100 \mu \mathrm{L}$ per animal) was administered to the mice by intraperitoneal injection for determining the optical intensity of Raji-Luc cells in each animal using IVIS Lumina III (Perkin Elmer). Animals bearing the RajiLuc cells were subsequently randomized into 4 groups (12 males and 12 females each) according to their fluorescence intensity.

The clinical dose of CD19-positive CART cells is $10^{7} / \mathrm{kg}$, which is estimated as $1 \times 10^{8} / \mathrm{kg}$ for mouse, which is equivalent to $0.2 \times 10^{7}$ per animal (the body mass of a mouse is considered to be $0.02 \mathrm{~kg}$, and the body surface area is considered to be 10 folds that of a human). Considering that the CD19-positive CAR-T cell rate is estimated as $21.8 \%, 0.83 \times 10^{8}$ total cells per animal were given to the animals when $1.8 \times 10^{7} \mathrm{CD} 19$-positive CART cell per animal were dosed, which is just less than the maximum number of cells a mouse can tolerate $\left(1 \times 10^{8}\right.$ per animal). Thus, $0.2 \times 10^{7}$,
$0.6 \times 10^{7}$ and $1.8 \times 10^{7}$ CART19 cells per animal were singledosed to the mice via intravenous injection on $\mathrm{d} 1 \mathrm{(96 \textrm {h }}$ after animals were administered Raji-Luc cells). The mice in the Buffer group were administered an equal volume of freezing buffer, and the Untreated group without tumor xenografting was administered freezing buffer in parallel.

For pharmacodynamics and toxicity evaluations, clinical symptoms were observed every day, while the animals' body weights and the fluorescence intensities triggered by RajiLuc cells were measured every week. Blood $(0.2 \mathrm{~mL})$ was taken every week for detecting the humanized cytokine profiles (IL-2, IL-4, IL-6, IL-10, IFN- $\gamma$ and TNF) in mice.

Animals were anesthetized on d14, d28 and d56 with sodium pentobarbital for hematological analysis (parameters included, leukocyte, lymphocyte, erythrocyte and platelet counts) as well as $\mathrm{hCD}^{+}$and $\mathrm{hCD} 8^{+}$cell counting. In addition, full necropsies were performed, and the heart, lungs, liver, spleen, kidneys, brain, testis, epididymis, ovaries, uterus, abdomen skin, injection site (tail), duodenum, jejunum, ileum, and bone marrow were fixed in $10 \%$ formalin and underwent histopathological examination.

\section{Biodistribution study}

CART19 cells $\left(0.6 \times 10^{7}\right.$ cells $)$ were intravenously single dosed to 48 NSG mice ( 24 males, 24 females) followed by the administration of Raji-Luc cells $\left(5 \times 10^{5}\right.$ per animal) $96 \mathrm{~h}$ later (Table 1). Three animals were scarified every 7 days for $\mathrm{hCD} 45^{+} / \mathrm{hCD} 3^{+}$, hCD $45^{+} / \mathrm{hCD} 19^{+}$analysis using flow cytometry methods (FACSCalibur, BD Biosciences) and quantitative analyses of CART19 in different tissues using quantitative PCR as previously described (18), including blood, heart, lungs, liver, kidneys, spleen, brain, stomach, duodenum, uterus, ovaries, testis, epididymis, bone marrow, adipose tissue and skeletal muscle. In brief, DNA from different tissues was extracted using a DNeasy Blood \& Tissue Kit (Qiagen) following the manufacturer's instructions, while the concentrations of eluted DNA were quantified using UV spectrophotometry and adjusted to a suitable concentration range. The sequence of exogenous CART19 fragment is "TGCCGATTTCCAGAAGAAGAA GAAGGAGGATGTGAACTGAGA GTGAAGTTCAGC AGGAGCGC", while the sequence of internal reference $\beta$-actin is "TGTCACTCTTCTCTTAGGTATGGAAT CCTGTGGCATCCATGAAACTACATTCAATTCCAT CATGAAGTGTGACGTTGACATCCGTAAAGACC”. Primers and probes for CART19 and $\beta$-actin were designed 
Table 1 Study design for preclinical safety evaluation of CART19

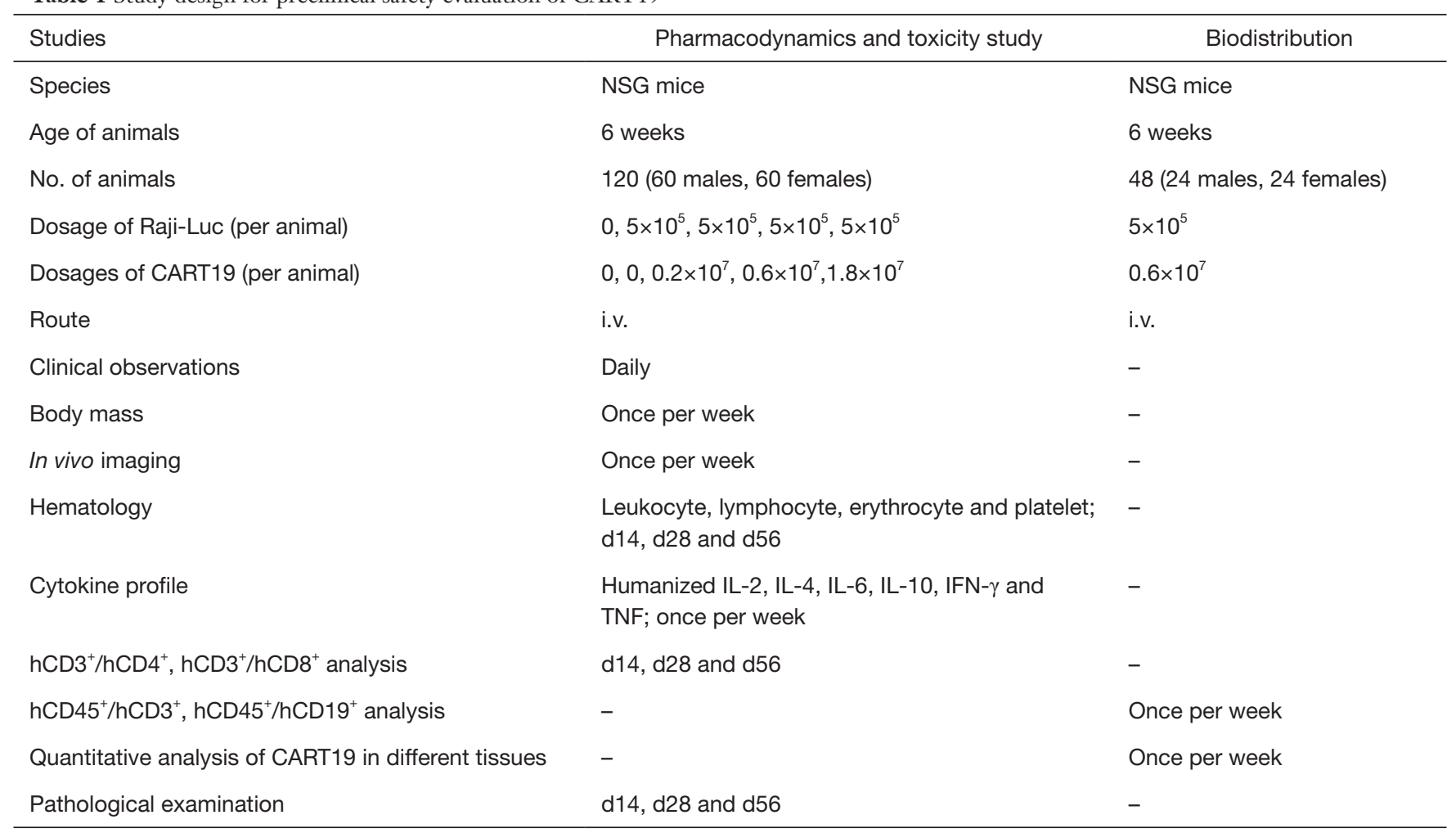

Table 2 Sequences of primers and probes for CART19 and $\beta$-actin

\begin{tabular}{ll}
\hline Primers & Sequence (5' to 3') \\
\hline CART19 & TGCCGATTCCAGAAGAAGAAGAAG \\
Forward primer & GCGCTCCTGCTGAACTTC \\
Backward primer & FAM-GAGGATGTGAACTGAGAGT-MGB \\
Probe & \\
$\beta$-actin & TGTCACTCTTCTCTTAGGTATGGA \\
Forward primer & GGTCTTTACGGATGTCAACG \\
Backward primer & FAM-TCCTGTGGCATCCATGAAACTAC-BHQ1 \\
Probe &
\end{tabular}

and synthesized by Sangon Biotech (Shanghai, China) as listed in Table 2.

\section{Statistical analysis}

All data represent the means \pm standard deviations (SDs) of $n$ values, where $n$ corresponds to the number of mice used. A Kaplan-Meier curve was plotted for estimating the survival rate of animals. Other statistical analyses were performed using one-way ANOVA, followed by Dunnett's test for comparisons against the Untreated or Buffer group. The figures were plotted using GraphPad Prism 5 for Windows (GraphPad Software, San Diego, CA, USA), and the statistical significance was determined using SPSS (ver.12), as values were considered significantly different when $\mathrm{P}<0.05$. 
A

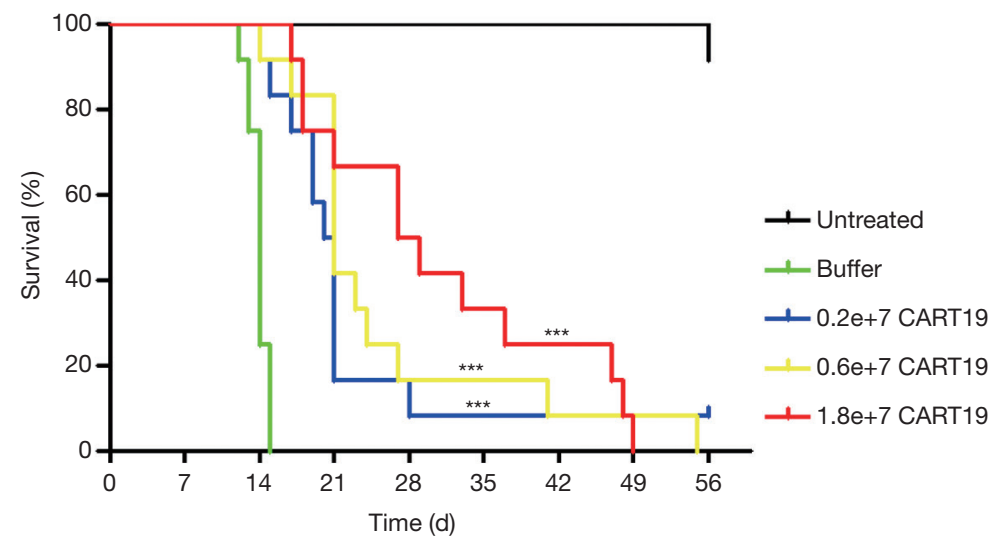

B

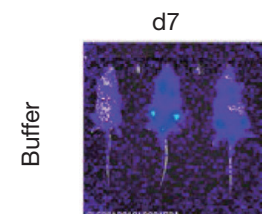

d14

d21

d28

d35
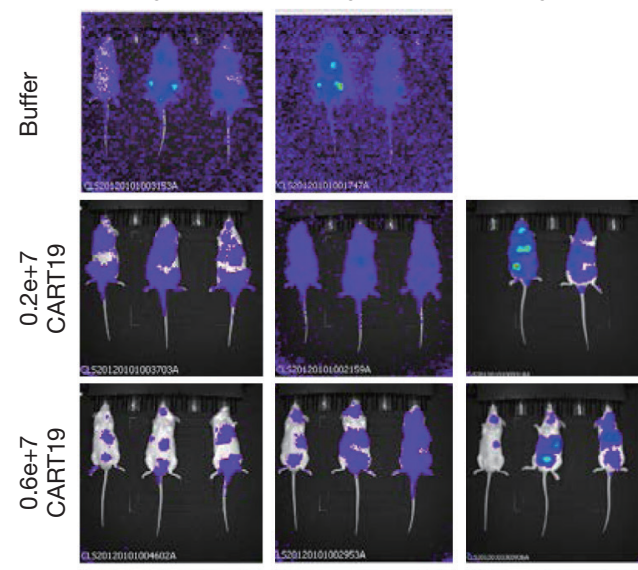

(1)
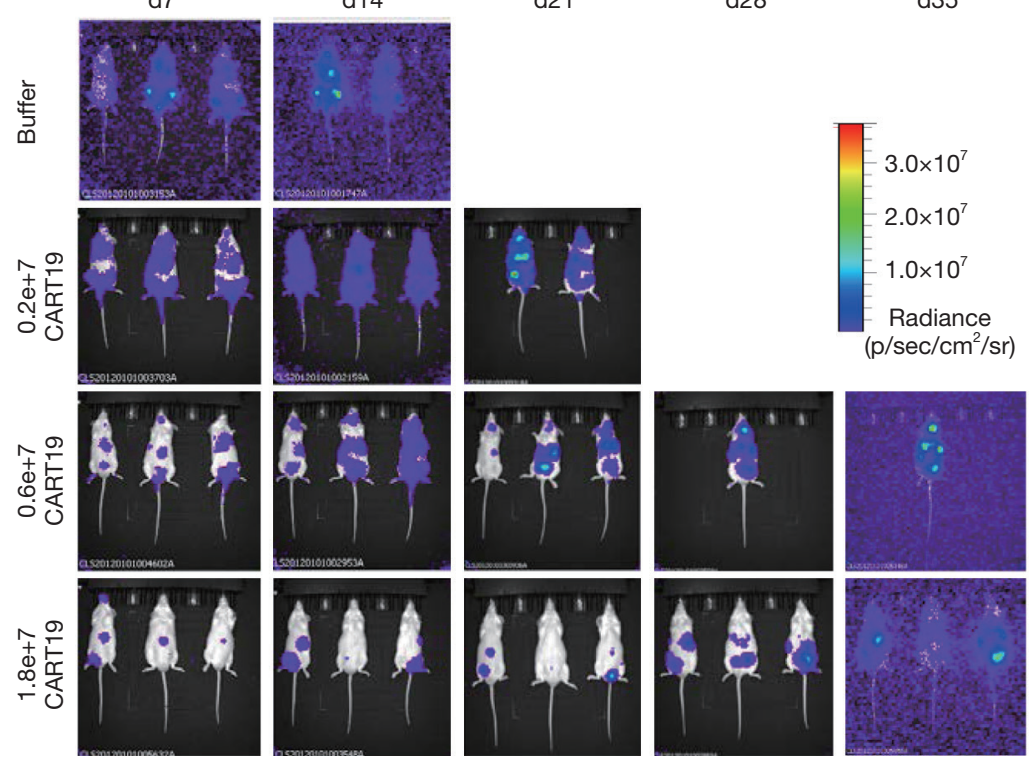

Figure 1 Survival analysis in NSG mice administrated with CART19. (A) Mean survival rate of animals were demonstrated and analyzed using Kaplan-Meier analysis, as significant increases of survival rates can be found in all groups administrated with CART19 comparing to the Buffer group (***, $\mathrm{P}<0.001$ ); (B) in vivo fluorescence intensity of animals xenografted with Raji-Luc were visualized and the mean fluorescence intensities in animals administrated with CART19 were markedly lower than Buffer group since 7 days after administration.

\section{Results}

\section{CART19 increases the survival in NSG mice bearing Raji cells}

The mean survival times of NSG mice in the blank control (Untreated) group, tumor-bearing NSG mice in the buffer (Buffer) group, the CART19 0.2e+7 group, the CART19 $0.6 \mathrm{e}+7$ group and the CART19 $1.8 \mathrm{e}+7$ group were approximately over 56,13.5, 20, 20.5 and 27 days respectively (Figure 1A, Table 3). For the Untreated group, 11 out of 12 animals survived until the end of the study, and immunodeficiency was therefore substantially excluded from the major causes of death for the animals in this study. In contrast, all animals bearing Raji cells and buffer were dead between 10 to 15 days after administration, indicating the success of tumor xenografting. The survival rates of animals administered different doses of CART19 via the caudal vein were $83 \%, 92 \%$ and $100 \%$ on $\mathrm{d} 15$, and $8 \%$, $17 \%$ and $42 \%$ on $\mathrm{d} 29$, which demonstrated the trend of dose-survival dependence. According to the Kaplan-Meier analysis, significant difference was found from the CART19 $0.2 \mathrm{e}+7$ group, indicating the contribution of CART19 in the improvement of the animal survival rate $(\mathrm{P}<0.001)$.

The in vivo fluorescence intensity level of Raji-Luc cell 


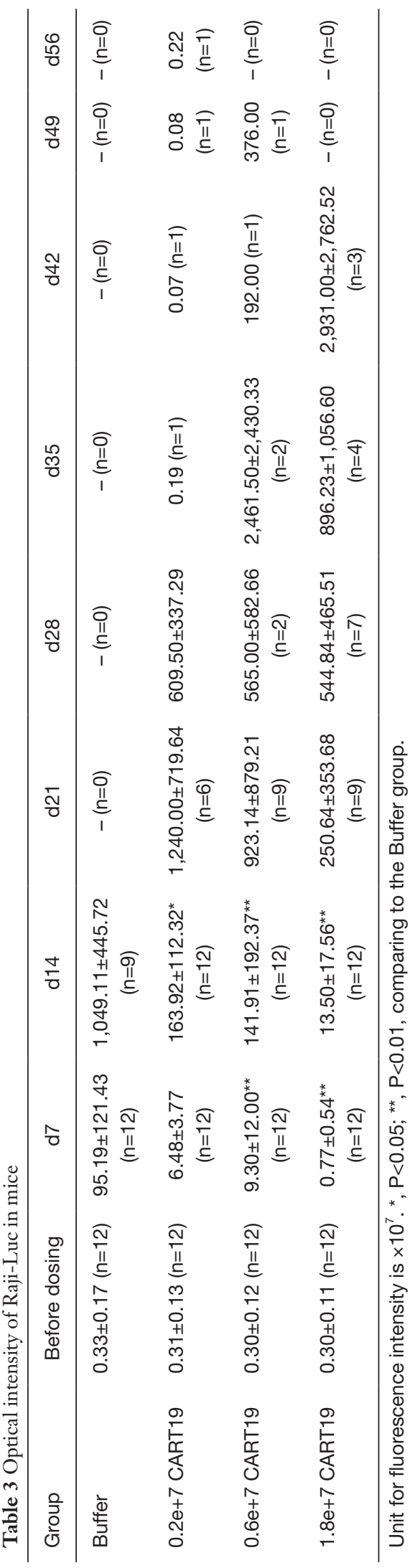

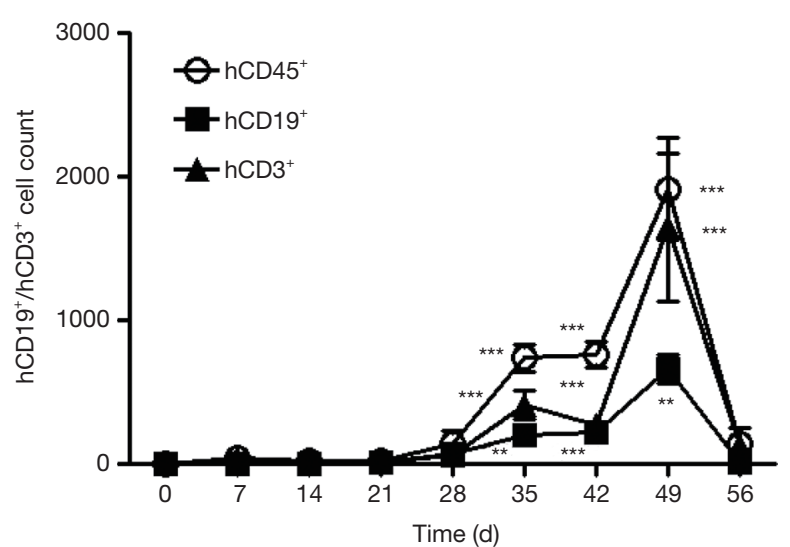

Figure 2 Proliferation of lymphocytes with hCD19+, hCD3 ${ }^{+}$ and $\mathrm{hCD} 45^{+}$in animals administrated with $0.6 \mathrm{e}+7$ CART19. Lymphocytes expressing hCD $19^{+}$for human B lymphocytes Raji-Luc was markedly increased in the NSG mice since 28 days after administration (**, $\mathrm{P}<0.01$; ***, $\mathrm{P}<0.001$ ), while a significant increase of $\mathrm{hCD}^{+}$for human $\mathrm{T}$ lymphocytes CART19 was also observed in the meanwhile $\left.{ }^{* * *}, \mathrm{P}<0.001\right)$.

reflects the proliferation and distribution of tumor cells in the animals (Figure $1 \mathrm{~B}$ ), and the maximum intensity corresponding to the maximum tumor cell the animals could tolerate was approximately e +10 . The average intensities of animals in the CART19 $0.2 \mathrm{e}+7$ group, the CART19 0.6e+7 group and the CART19 1.8e+7 group were approximately $1 / 10,1 / 10$ and $1 / 100$ of the buffer group $(\mathrm{P}<0.05, \mathrm{P}<0.01) 2$ weeks after administration, showing a dose-response relationship. A total of $50 \%$ of animals in the CART19 0.2e+7 group and the CART19 0.6e+7 group were found dead 3 to 4 weeks after administration, and death was observed 4 to 5 weeks after administration for animals in the CART19 $1.8 \mathrm{e}+7$ group. Thus, the changes in fluorescence intensity were positively correlated with the survival rate.

\section{Biodistribution analysis of CART19 in NSG mice}

In this study, hCD $19^{+}$is targeted at Raji-Luc human B lymphocytes, while hCD ${ }^{+}$recognizes the CART19 human $\mathrm{T}$ lymphocytes in the immunodeficient mice. For the Untreated group, only hCD $19^{+}$was detected, and the averaged value of $\mathrm{hCD} 19^{+}$was 27 folds over that measured in the first week (Figure 2). Both hCD $19^{+}$and $\mathrm{hCD}^{+}$levels in animals dosed with CART19 had increased markedly since 4 weeks after administration, peaking after 7 weeks $(\mathrm{P}<0.001)$. The mean hCD3 ${ }^{+}$levels in the CART19 0.2 e+7, $0.6 \mathrm{e}+7$ and $1.8 \mathrm{e}+7$ groups were higher than the hCD $19^{+}$ 
Table 4 Copies of CART19 sequence in different tissues of NSG mice (copies/ng DNA)

\begin{tabular}{|c|c|c|c|c|c|c|c|c|c|}
\hline Tissues & $\mathrm{d} 0$ & $\mathrm{~d} 7$ & d14 & $\mathrm{d} 21$ & $\mathrm{~d} 28$ & d35 & $\mathrm{d} 42$ & $\mathrm{~d} 49$ & d56 \\
\hline Heart & N.D. & N.D. & N.D. & N.D. & $11.1 \pm 2.3$ & $36.6 \pm 26.8$ & $152.1 \pm 96.4$ & $108.2 \pm 108.6$ & 145.0 \\
\hline Lungs & N.D. & $10.9 \pm 1.2$ & $5.8 \pm 0.5$ & $6.7 \pm 0.9$ & $56.2 \pm 20.3$ & $150.2 \pm 51.4$ & $41.2 \pm 16.8$ & $1,885.1 \pm 208.2$ & $126.2 \pm 45.6$ \\
\hline Liver & N.D. & N.D. & N.D. & 4.59 & $30.6 \pm 11.9$ & $89.2 \pm 18.4$ & $28.5 \pm 10.3$ & $244.6 \pm 124.0$ & $223.0 \pm 110.0$ \\
\hline Spleen & N.D. & $6.1 \pm 0.7$ & N.D. & N.D. & $34.3 \pm 8.1$ & $83.9 \pm 27.9$ & $19.5 \pm 3.5$ & $755.5 \pm 224.0$ & $46.1 \pm 36.9$ \\
\hline Brain & N.D. & N.D. & 8.62 & N.D. & $9.5 \pm 2.1$ & $35.5 \pm 3.2$ & $81.3 \pm 54.1$ & $68.0 \pm 25.1$ & N.D. \\
\hline Stomach & N.D. & N.D. & N.D. & 35.16 & $7.3 \pm 0.8$ & $8.0 \pm 1.3$ & 3.7 & $470.8 \pm 370.2$ & 34.6 \\
\hline Duodenum & N.D. & N.D. & N.D. & N.D. & $10.3 \pm 0.6$ & 9.2 & 8.8 & $91.7 \pm 45.0$ & 28.7 \\
\hline Testis & N.D. & N.D. & N.D. & N.D. & 6.4 & $84.9 \pm 51.0$ & $5.0 \pm 0.0$ & N.D. & N.D. \\
\hline Epididymis & N.D. & N.D. & N.D. & N.D. & $12.7 \pm 4.3$ & 4.9 & N.D. & N.D. & 5.7 \\
\hline Bone marrow & N.D. & N.D. & N.D. & $8.6 \pm 0.9$ & $88.8 \pm 46.4$ & $98.2 \pm 49.7$ & 8.9 & $980.4 \pm 274.4$ & $53.1 \pm 23.5$ \\
\hline Adipose tissue & N.D. & N.D. & 280.99 & N.D. & $52.0 \pm 26.0$ & $67.0 \pm 24.9$ & $38.2 \pm 23.6$ & $709.0 \pm 250.7$ & N.D. \\
\hline Skeletal muscle & N.D. & N.D. & N.D. & N.D. & $16.8 \pm 5.1$ & $68.7 \pm 23.4$ & $9.8 \pm 1.0$ & $308.2 \pm 194.3$ & 37.5 \\
\hline
\end{tabular}

N.D., not defined.

levels from 5 weeks after administration $(\mathrm{P}<0.001)$ However, reductions in the total leukocyte counts of animals dosed with CART19 were observed 56 days after administration, possibly associated with the progress of tumorigenesis.

CART19 sequence copy numbers in different tissues were determined by quantitative PCR (Table 4). CART19 could be detected from the ovary, uterus, spleen and lung 1 week after administration, suggesting that these tissues could be the primarily targets of CART19. From 4 to 5 weeks after administration, the contents of CART19 in all tissues had markedly increased, suggesting that CART19 had been extensively distributed throughout the body via the circulation at this time. The peak values could be detected after 7 weeks with a trend in accord with the $\mathrm{CD}^{+}$ count in the peripheral blood, and tissues demonstrating the highest CART19 counts were the lungs, bone marrow, spleen, liver, skeletal muscle and fat, respectively. As the lungs are richly perfused with blood and are the primary target of the infused cells, the CART19 levels remained high from the first week after administration. In general, CART19 were gradually traveled through all major organs and tissues and accumulated along with its steadily proliferation in vivo.

\section{General toxicity}

No animals in the Untreated group showed abnormal clinical symptoms during the study. Most of the animals in the Buffer group demonstrated paralysis, and a few showed abdominal swelling and, narrowed eyes and lay prostrate (Table 5). Paralysis, abdominal swelling and lay prostate could result from tumor invasion on the spinal cord and the nervous system. In addition to the above symptoms, tremor, roachback, piloerection, reduced activity and hypothermia were also observed in animals administered CART19. Except for one male animal in the $0.2 \mathrm{e}+7$ group, all other animals showing the above symptoms were dead within a short time period. The fluorescence intensity of Raji-Luc cells in this survivor peaked at 3 weeks after administration, and gradually reduced to the baseline level by 5 weeks when the roachback and piloerection symptoms also disappeared. Hypothermia might be associated with the anemia induced by the development of the tumor, while the decreased activity was a manifestation of the reduction of overall 
Table 5 Clinical symptoms and occurrences

\begin{tabular}{|c|c|c|c|c|c|c|c|c|c|c|}
\hline $\begin{array}{l}\text { Clinical } \\
\text { observations }\end{array}$ & \multicolumn{2}{|c|}{ Untreated } & \multicolumn{2}{|c|}{ Buffer } & \multicolumn{2}{|c|}{$0.2 e+7$ CART19 } & \multicolumn{2}{|c|}{$0.6 \mathrm{e}+7 \mathrm{CART} 19$} & \multicolumn{2}{|c|}{$1.8 \mathrm{e}+7 \mathrm{CART} 19$} \\
\hline Normal & $12 / 12$ & $12 / 12$ & $2 / 12$ & $1 / 12$ & $5 / 12$ & $5 / 12$ & $10 / 12$ & $4 / 12$ & $10 / 12$ & $8 / 12$ \\
\hline Abdominal swelling & $0 / 12$ & $0 / 12$ & $1 / 12$ & $0 / 12$ & $2 / 12$ & $0 / 12$ & $0 / 12$ & $0 / 12$ & $0 / 12$ & $0 / 12$ \\
\hline Narrowed eyes & $0 / 12$ & $0 / 12$ & $1 / 12$ & $0 / 12$ & $2 / 12$ & $0 / 12$ & $2 / 12$ & $1 / 12$ & $0 / 12$ & $1 / 12$ \\
\hline Paralysis & $0 / 12$ & $0 / 12$ & $9 / 12$ & $11 / 12$ & $1 / 12$ & $7 / 12$ & $2 / 12$ & $7 / 12$ & $0 / 12$ & $3 / 12$ \\
\hline Tremor & $0 / 12$ & $0 / 12$ & $0 / 12$ & $0 / 12$ & $1 / 12$ & $0 / 12$ & $0 / 12$ & $0 / 12$ & $0 / 12$ & $0 / 12$ \\
\hline Roachback & $0 / 12$ & $0 / 12$ & $0 / 12$ & $0 / 12$ & $2 / 12$ & $0 / 12$ & $2 / 12$ & $1 / 12$ & $1 / 12$ & $1 / 12$ \\
\hline Piloerection & $0 / 12$ & $0 / 12$ & $0 / 12$ & $0 / 12$ & $2 / 12$ & $0 / 12$ & $2 / 12$ & $1 / 12$ & $1 / 12$ & $1 / 12$ \\
\hline
\end{tabular}
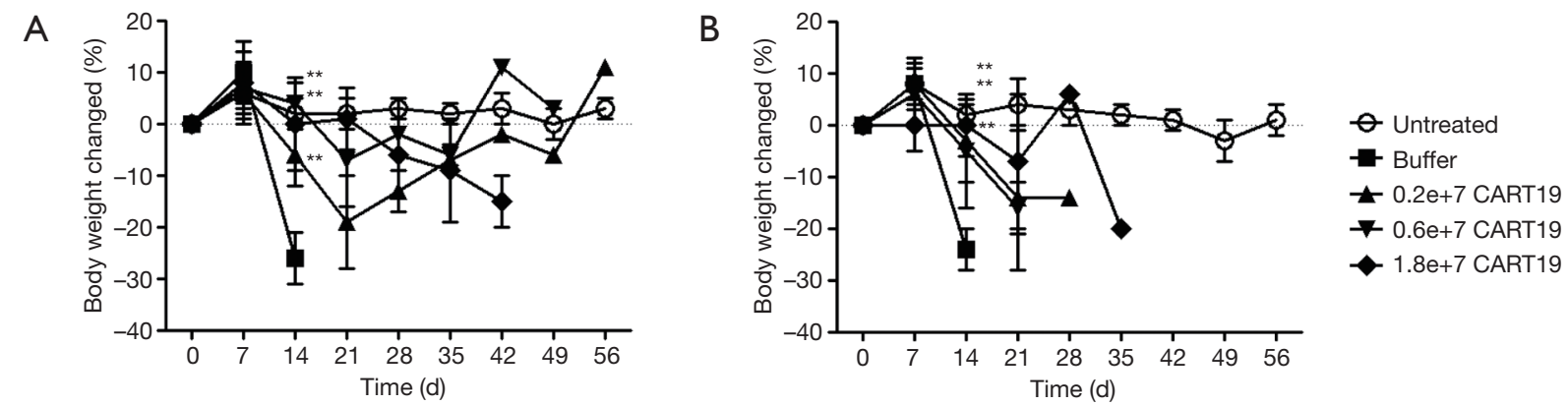

Figure 3 Changes on body mass in NSG mice over 56 days after administrated with CART19. Percentage changes of male (A) and female (B) NSG mice body mass in different groups were demonstrated, and those administrated with CART19 showed a less body mass loss than the Buffer group $\left({ }^{* *}, \mathrm{P}<0.01\right)$.

tolerance to CART19.

The body masses of animals dosed with CART19 were higher than those of the buffer group (Figure 3, $\mathrm{P}<0.01$ ) at 2 weeks after administration, and a dose-response dependent trend was detected from 3 weeks after administration. Hence, CART19 was able to slow down the mass loss caused by Raji-Luc cells.

\section{Effect of CART19 on peripheral blood cells}

The lymphocyte count in the CART19 $0.2 \mathrm{e}+7$ group was higher than that of the Untreated group 2 weeks after administration $(\mathrm{P}<0.05)$, which might be attributed to the infusion of CART19, but not the toxic effect (Figure 4). However, no such change was observed in animals bearing higher doses of CART19 or 3/4 weeks after administration, as many of the lymphocytes might be consumed against Raji-Luc or might be present in the tissues. In addition, no differences were found in the WBC, RBC and PLT counts among all groups, suggesting that CART19 had no evident effects on the hematologic system in NSG mice.

The averaged expression levels of $\mathrm{hCD}^{+}, \mathrm{hCD}^{+}$and $\mathrm{hCD}^{+}$in animals administered CART19, especially those in the CART19 $1.8 \mathrm{e}+7$ group were increased compared with the animals dosed with buffer $(\mathrm{P}<0.01)$ after 2 weeks, and the levels of $\mathrm{CD}^{+}$killer $\mathrm{T}$ cells were slightly higher than those of $\mathrm{hCD}^{+}$cells, which was determined by the characteristics of CART19 (Table 6). The hCD3 ${ }^{+}, \mathrm{hCD}^{+}$ and $\mathrm{hCD}^{+}$expression levels in the CART19 $0.2 \mathrm{e}+7$ group were significantly higher than those in the Untreated 
A

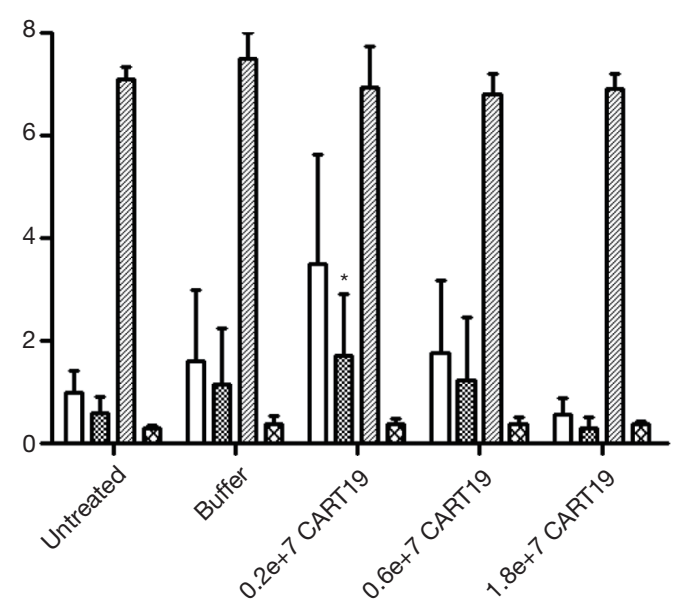

B

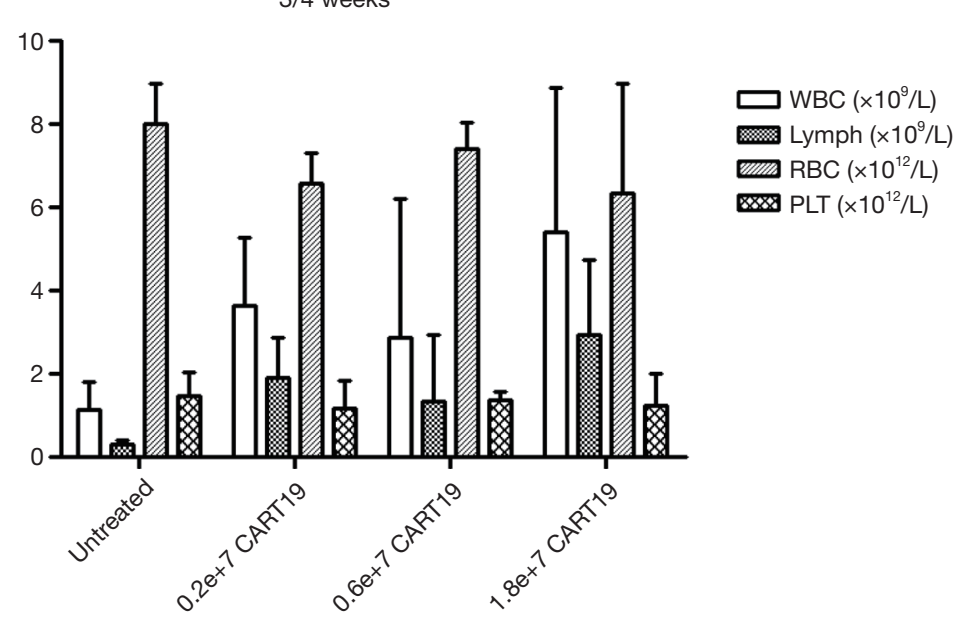

Figure 4 Hematology examination data in NSG mice after administrated with CART19. Averaged counts of leukocyte (WBC), lymphocytes (Lymph), erythrocyte (RBC) and platelet (PLT) in different groups on 2 weeks (A) or 3/4 weeks (B) after administrated with CART19 were showed as above $(*, \mathrm{P}<0.05)$. Animals in groups infused with CART19 showed no significant influence on the counts of total WBC, RBC and PLT, and the increase of Lymph in animals bearing CART19 is associate with the cell infusion.

Table $6 \mathrm{hCD}^{+}, \mathrm{hCD}^{+}$and hCD8 ${ }^{+}$counts per $10^{4} \mathrm{WBC}$ in NSG mouse

\begin{tabular}{|c|c|c|c|c|c|c|}
\hline Group & \multicolumn{3}{|c|}{ d14 } & \multicolumn{3}{|c|}{ d21/d28 } \\
\hline Untreated & $4 \pm 2$ & $0 \pm 0$ & $2 \pm 3$ & $10 \pm 5$ & $0 \pm 0$ & $3 \pm 2$ \\
\hline Buffer & $6 \pm 3$ & $0 \pm 0$ & $3 \pm 1$ & - & - & - \\
\hline $0.2 \mathrm{e}+7 \mathrm{CART} 19$ & $30 \pm 29$ & $1 \pm 1$ & $21 \pm 24^{*}$ & $1,437 \pm 1,386^{\#}$ & $51 \pm 58^{\# \#}$ & $1,096 \pm 1,026^{\# \#}$ \\
\hline 1.8e+7 CART19 & $52 \pm 34^{\star *}$ & $16 \pm 12^{\star *}$ & $19 \pm 14^{\star *}$ & $206 \pm 293$ & $9 \pm 10^{\#}$ & $168 \pm 251$ \\
\hline
\end{tabular}

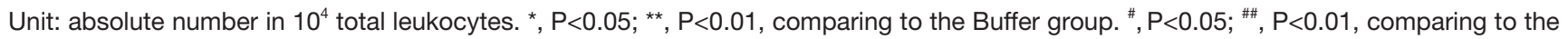
Untreated group.

group $(\mathrm{P}<0.05, \mathrm{P}<0.01)$, the $0.6 \mathrm{e}+7$ group and the $1.8 \mathrm{e}+7$ group, particularly the hCD8 ${ }^{+}$level. This phenomenon might be related to the malignant proliferation of Raji cells in animals, and a large amount of human $\mathrm{T}$ cells were consumed by attacking tumor cells, which is consistent with the expected pharmacodynamic effects of CART19.

\section{Human pro-inflammatory cytokine profile in NSG mice treated with CART19}

IFN- $\gamma$ and IL-10 are the two most sensitive cytokines that can be detected 1 week after the administration of CART19. IFN- $\gamma$ was detected only in the animals dosed with
CART19, reflecting its anti-tumor activity, whereas IL10 was highly expressed in all animals dosed with Raji-Luc (Figure 5). Decreases in the levels of IL-10 in the CART19 administration groups demonstrated the dose-response relationship 2 weeks after administration (compared with buffer group, $\mathrm{P}<0.05, \mathrm{P}<0.01, \mathrm{P}<0.001$ ), suggesting the inhibitory effects of CART19 on tumor proliferation. Small amounts of TNF for tumor killing and IL-6, which promotes $\mathrm{B}$ cell activation and proliferation were detected 2 weeks after CART19 administration, and the latter increased over time by 3 and 4 weeks after administration. The above results suggested that CART19 proliferated in the mice and exerted a certain tumor killing effect, while no 


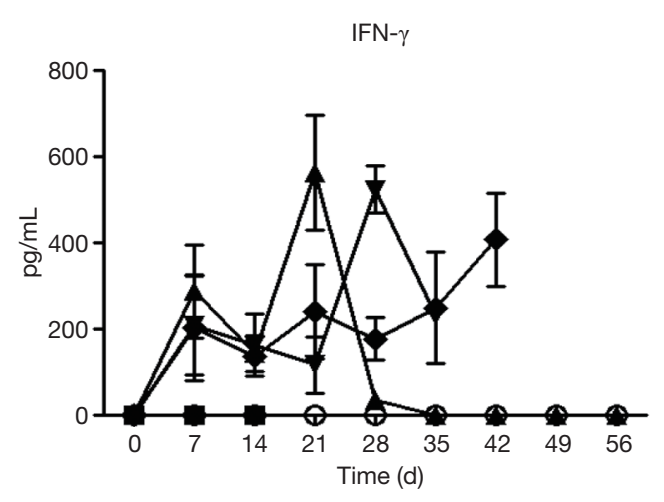

IL-10

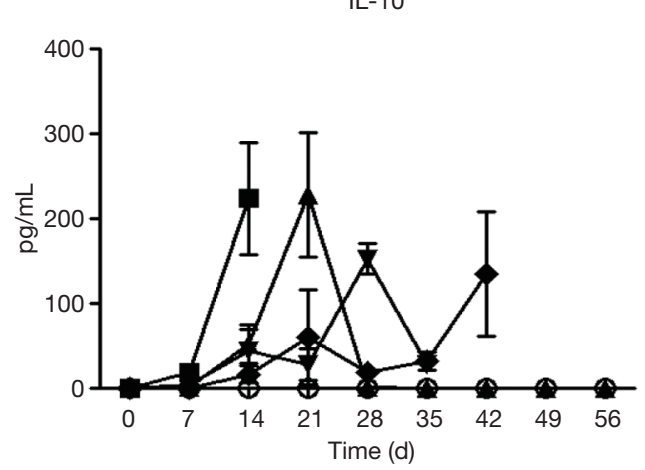

TNF

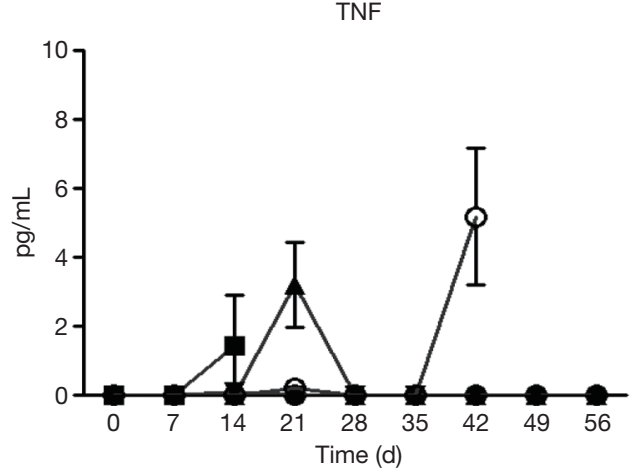

IL-6

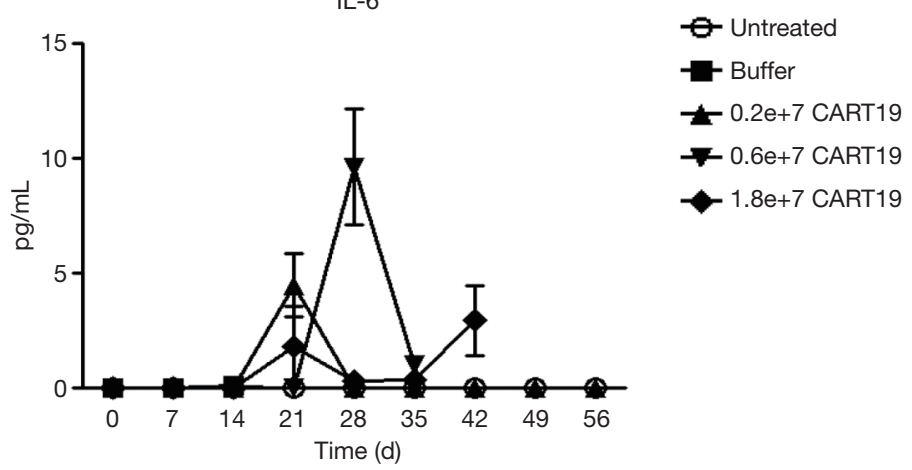

Figure 5 Humanized cytokine profiles in NSG mice administrated with CART19. Averaged levels of humanized IL-6, IL-10, IFN- $\gamma$ and TNF in immunodeficiency mice were demonstrated. IFN- $\gamma$ was only found in the mice dosed with CART19, while IL-10 was expressed in all animals xenografted with Raji-Luc and showed a decrease along with the increased concentration of CART19. A small amount of TNF and IL-6 were detected since 2 weeks after administrated with CART19.

excessive immune response was observed.

\section{Pathological features}

Lymphoma observed in the mice resulted from the xenografting of Raji-Luc cells, and appeared as white spots in the liver, nodules in the spleen, kidney, uterine, prostate, pituitary, epididymis, spine, and stomach, and enlarged ovaries at necropsy (Figure $6 A, B, C, D$ ). The incidence rates of lymphoma (Table 7) in the liver, spleen, kidney, lung, brain, and sternum with marrow showed decreasing tends when comparing the Buffer group to the CART19 $1.8 \mathrm{e}+7$ group on the $14^{\text {th }}$ day after administration, while no significant dose-response relationship was observed on the $28^{\text {th }}$ day after administration. However, in animals sacrificed on the $28^{\text {th }}$ day, lymphoma had also infiltrated the heart, pituitary, stomach, intestines, spine, and male reproductive organs. The growth and metastasis of Raji-Luc cells were gradually exacerbated over time, which was the main cause of animal death. Meanwhile, animals administered CART19 experienced growth inhibitions of Raji-Luc cells from $14^{\text {th }}$ days after administration.

The major histopathological changes (Table 8) associated with the administration of CART19 were the aggregation of CART19 cells and scattered mononuclear macrophages in the splenic sinusoid., which was attributed to the increased spleen size in the macroscopic findings (Figure 6E,F,G,H). The aggregation of CART19 and macrophages can also be observed in the liver, lung, kidney, brain, heart, capsule of the epididymis and intestines (Figure 6I,7).

In addition, suppurative inflammation of the heart and brain, necrosis and fibrosis of the liver, infarction and papillary suppurative inflammation with tubular necrosis of the kidney, and decreased bone marrow cells were seen in both the Buffer and CART19 groups, possibly attributed to the reaction of GvHD excited by CAR-T cell implantation; secondary to malignant tumors, the side effects induced by CART19 are generally associated with the tumor load (19). 

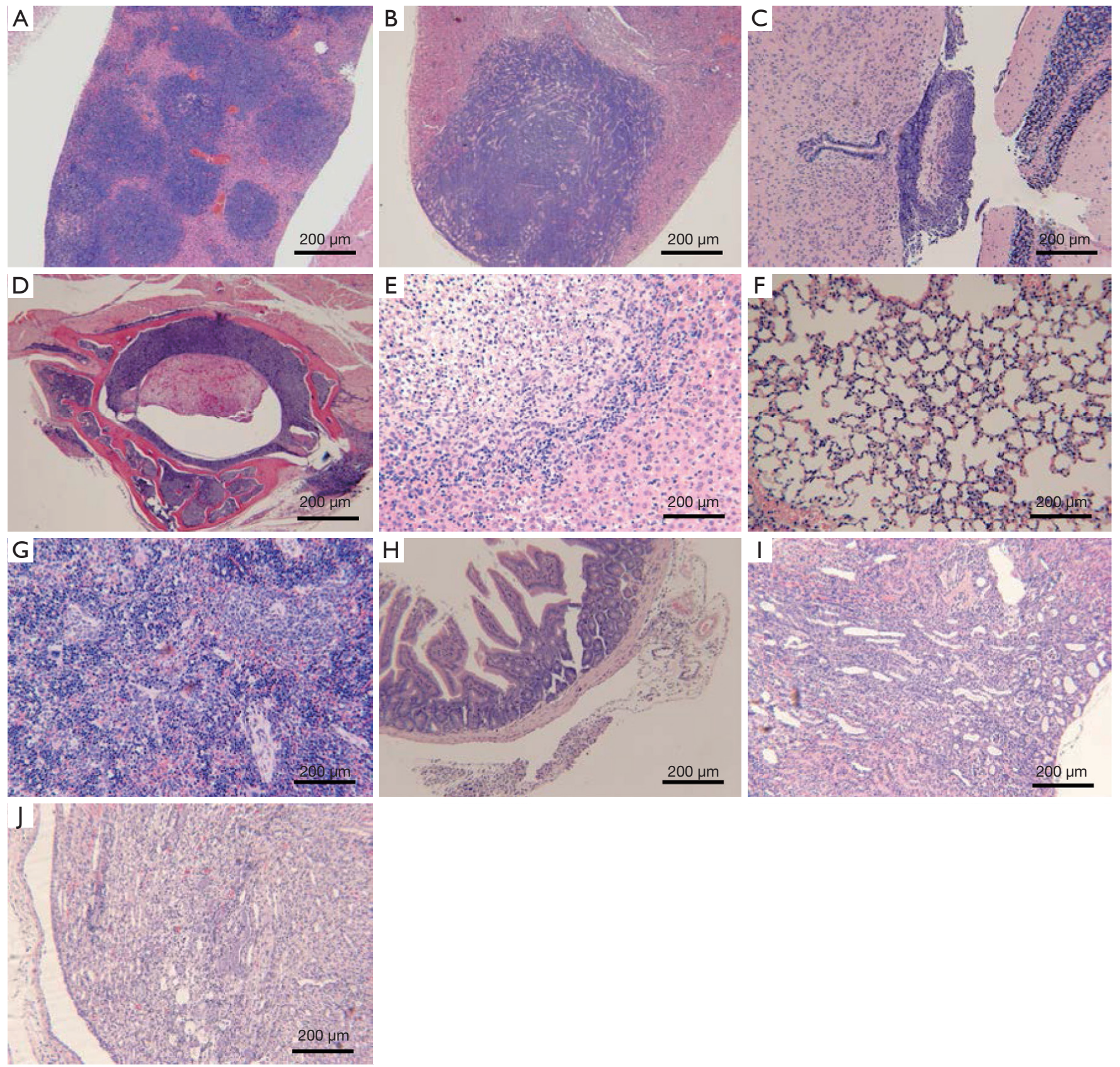

Figure 6 Histopathological changes in NSG mice. Typical histopathological changes were demonstrated as above. Lymphoma was observed in liver (A, 40x), kidney (B, 40x), pia mater of brain (C, 100×) and spinal cavity (D, 40×) in animals administrated with Raji-Luc cells, while aggregation of CAR-T cells following immune-related cells in the liver (E, 200x), lung (F, 200x), spleen (200x) and capsule of duodenum $(100 \times)$ was observed in animals administrated with CART19. Kidney is the primary toxicological target of CART19, as infarction (I, 100 $\times)$ and papillary suppurative inflammation with tubular necrosis of kidney (J, 100x) were observed in animals administrated with CART19.

\section{Discussion}

Despite the striking breakthrough of CAR-T therapy in terms of its clinical curative effects, its life-threatening toxic risk should not be overlooked. There is currently a lack of recommendable safety evaluation guidelines for CAR-T products, and customized study designs in line 
Table 7 Summary of lymphoma incidence in NSG mice administered with CART19

\begin{tabular}{|c|c|c|c|c|}
\hline Organ with lymphoma & \multicolumn{4}{|c|}{ Lymphoma incidence* } \\
\hline \multicolumn{5}{|l|}{ Liver } \\
\hline 14 days after dosing & $2 / 2$ & $5 / 5$ & $5 / 6$ & $1 / 3$ \\
\hline 28 days after dosing & - & $2 / 2$ & $2 / 3$ & $4 / 5$ \\
\hline \multicolumn{5}{|l|}{ Spleen } \\
\hline 14 days after dosing & $2 / 2$ & $3 / 5$ & $3 / 6$ & $0 / 3$ \\
\hline 28 days after dosing & - & $1 / 2$ & $0 / 3$ & $3 / 5$ \\
\hline Found dead & $17 / 22$ & $13 / 16$ & $9 / 15$ & $9 / 13$ \\
\hline 28 days after dosing & - & $1 / 2$ & $1 / 3$ & $3 / 5$ \\
\hline Found dead & $14 / 22$ & $14 / 16$ & $11 / 15$ & $9 / 13$ \\
\hline \multicolumn{5}{|l|}{ Lung } \\
\hline 14 days after dosing & $2 / 2$ & $4 / 5$ & $0 / 6$ & $1 / 3$ \\
\hline 28 days after dosing & - & $1 / 2$ & $0 / 3$ & $2 / 5$ \\
\hline Found dead & $17 / 22$ & $11 / 16$ & $8 / 15$ & $6 / 13$ \\
\hline Heart (found dead) & $0 / 22$ & $0 / 16$ & $2 / 15$ & $3 / 13$ \\
\hline \multicolumn{5}{|l|}{ Brain } \\
\hline \multicolumn{5}{|l|}{ Sternum with bone marrow } \\
\hline 28 days after dosing & - & $0 / 2$ & $0 / 3$ & $1 / 5$ \\
\hline Found dead & $17 / 22$ & $14 / 16$ & $10 / 15$ & $9 / 13$ \\
\hline Pituitary (found dead) & $0 / 22$ & $1 / 16$ & $2 / 15$ & $1 / 13$ \\
\hline Stomach (found dead) & $0 / 22$ & $0 / 16$ & $0 / 15$ & $1 / 13$ \\
\hline Duodenum (found dead) & $0 / 22$ & $1 / 16$ & $0 / 15$ & $0 / 13$ \\
\hline Jejunum (found dead) & $0 / 22$ & $0 / 16$ & $0 / 15$ & $1 / 13$ \\
\hline Ileum (found dead) & - & $0 / 2$ & $0 / 3$ & $1 / 5$ \\
\hline \multicolumn{5}{|l|}{ Spine } \\
\hline 28 days after dosing & - & $1 / 2$ & $0 / 3$ & $1 / 5$ \\
\hline Found dead & $0 / 22$ & $3 / 16$ & $3 / 15$ & $3 / 13$ \\
\hline Testis (found dead) & $0 / 10$ & $0 / 8$ & $1 / 6$ & $0 / 6$ \\
\hline
\end{tabular}

Table 7 (continued) 
Table 7 (continued)

\begin{tabular}{|c|c|c|c|c|}
\hline Organ with lymphoma & \multicolumn{4}{|c|}{ Lymphoma incidence* } \\
\hline Epididymis (found dead) & $0 / 10$ & $1 / 8$ & $1 / 6$ & $0 / 6$ \\
\hline Prostate (found dead) & - & $0 / 1$ & $1 / 3$ & - \\
\hline \multicolumn{5}{|l|}{ Uterus } \\
\hline 28 days after dosing & - & $1 / 1$ & - & $1 / 2$ \\
\hline Found dead & $1 / 12$ & $5 / 8$ & $5 / 9$ & $1 / 7$ \\
\hline \multicolumn{5}{|l|}{ Ovary } \\
\hline 14 days after dosing & - & $2 / 3$ & $1 / 3$ & $1 / 3$ \\
\hline
\end{tabular}

*, total number of males and females with lymphomas in various tissues/organs/total number of males and females examined by macroscopy in each group. When the tissue autolysis was found in dead animal, the macroscopic findings wasn't recorded. The incidence of lymphomas in all organs was recorded by histopathological examination on the day 14 and day 28 after administration, respectively. In addition, the lymphomas incidence of dead/moribund animals was listed separately for each group during the 56-day trial period. -: there were no animals to be executed as planned in the CAR-T cells dose group on the day 14/28 after administration. CAT-T, chimeric antigen receptor-modified T.

with the characteristics of CAR-T are required for reliable elucidation (20). The dose design is a paramount concern for both pharmacodynamics and toxicological studies. As unexpected death can occur when too many cells are given to the animals due to pulmonary embolism induced by cell clumps, the total amount of cells administered per animals should not exceed $10^{8}$. In addition, the dosage of CAR-T used in clinical practice is usually approximately $10^{6} / \mathrm{kg}$ to $10^{7} / \mathrm{kg}$, equivalent to $0.2 \times 10^{6}-0.2 \times 10^{7}$ per mouse $\left(10^{6} / \mathrm{kg}\right.$ or $10^{7} / \mathrm{kg}$ times $0.02 \mathrm{~kg}$ times the surface coefficient of 10$)$. In many cases, as the rate of CAR positive cells is no more than $50 \%$, the possible highest dosage for preclinical study is merely 10 to 30 times the clinical dose. Thus, the dose limitation allows the pharmacodynamic study to be combined with a toxicological study with the same dose range. Hereby, we performed a comprehensive evaluation focused on the distribution and immunotoxicity of CART19 by integrating tumor suppressive activity and toxicological indexes, including, survival rate, tumor clearance rate, animal clinical symptoms, body mass, blood cell count, cytokines, histopathological examination and distribution/ proliferation. A T cell control group was originally involved to distinguish the toxicities generated by the introduction of CARs or T cells themselves (21). Nevertheless, the toxicity of $T$ cells is substantially less targeted than that of the CAR-T, and might be exerted in a completely different pattern. Due to the cost and availability of using immunodeficient animals, a $\mathrm{T}$ cell control group was not included in this study, and the toxicological data reflected the overall toxicity of the CAR and T cells that constituted CART19. As a result, CART19 was widely distributed in the organs well-perfused with blood, including the lungs, blood, bone marrow, liver and spleen, as reported (22). It extensively spread all over the organs from 4 weeks after administration and peaked in the $7^{\text {th }}$ week after administration. Significant proliferation of CART19 was also found in the blood via detection using humanized $\mathrm{CD}^{+}$ for $\mathrm{T}$ lymphocytes. The survival rate and leukemia related clinical symptoms in mice administered CART19 were markedly ameliorated, and the proliferation of Raji cells in the mice was effectively inhibited. However, CART19 had no obvious effects on either the mean body mass or the blood cell counts, and no CRS was observed. In the present study, the dose at which CART19 could induce an excessive immune response was higher than $1.8 \times 10^{7} \mathrm{CD} 19$-positive CART cells per animal, which was equivalent to 9-fold human therapeutic use dosage, and the main toxicological targets were the liver, lungs, spleen, brain, heart, epididymis and intestine.

The most serious toxicity risk concern after CAR-T 
Table 8 Microscopic findings following the administration of CART19 in NSG mice

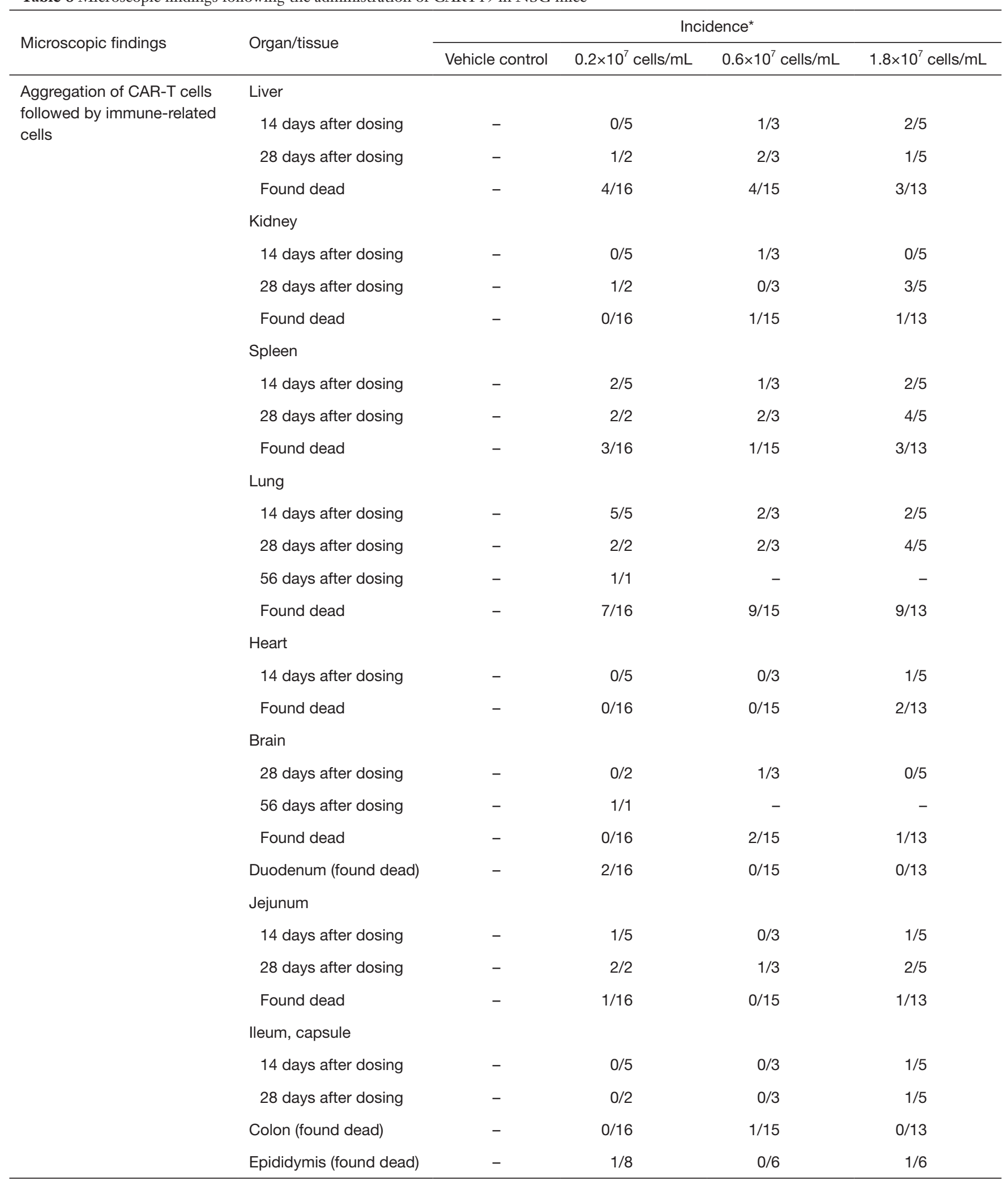

Table 8 (continued) 
Table 8 (continued)

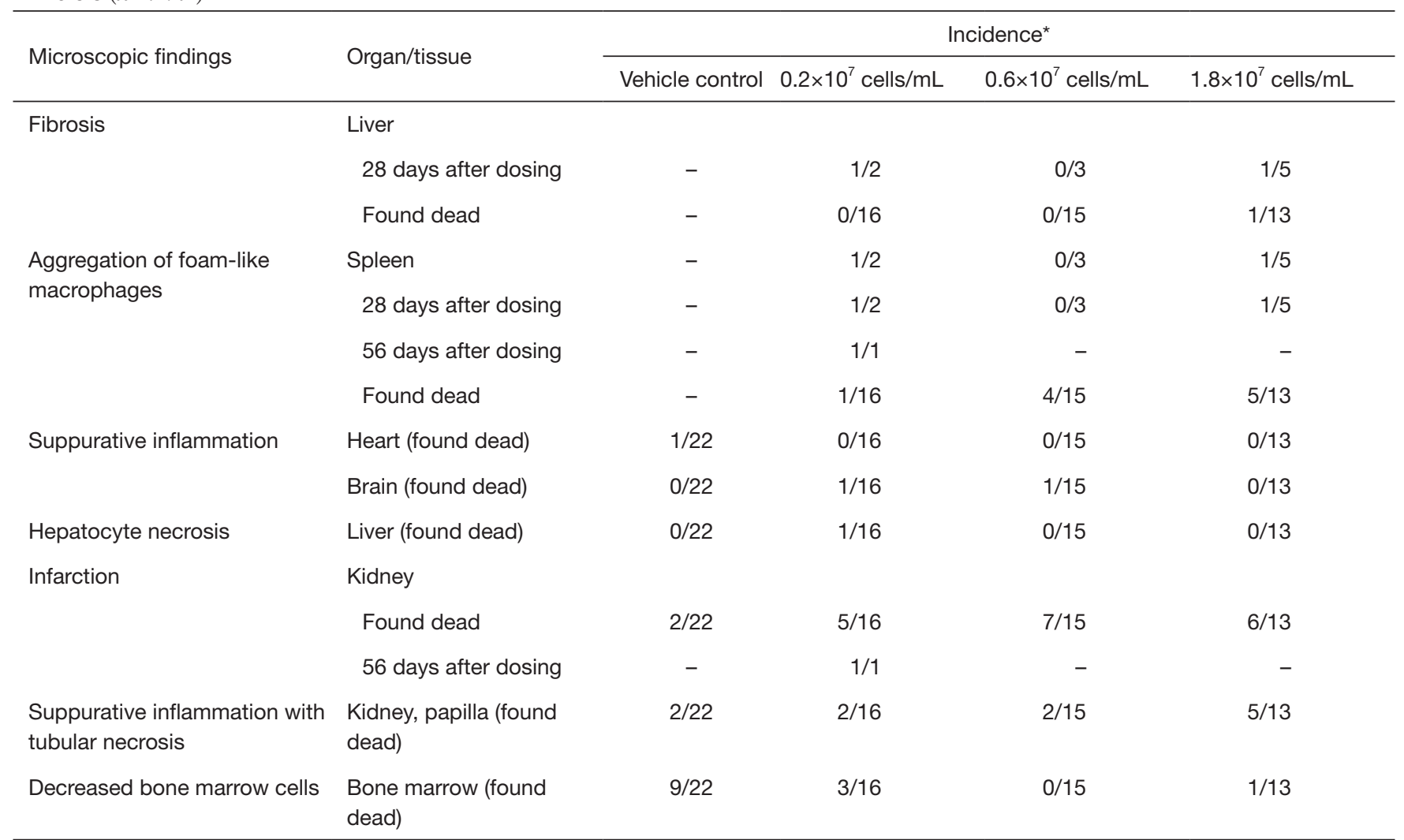

*, total number of males and females found these microscopic changes/total number of males and females examined by microscopy in each group. When the tissue autolysis was found in dead animal, the histopathological examination wasn't performed. The microscopic findings in all tissues/organs was recorded by histopathological examination on the day 14, day 28 , and day 56 after administration, respectively. In addition, the microscopic findings of dead/moribund animals were listed separately for each group during the 56-day trial period. -: there was no this histopathological change in the tissue/organ. CAT-T, chimeric antigen receptor-modified T.

treatment is CRS, which is also the target toxicity associated with the mechanism of action after CD19 CAR-T treatment (23). CRS is an acute and severe CD19 associated inflammatory response with tumor load. CAR-T-associated CRS relies on its antigen-to- $T$ cell activation, $T$ cell expansion and functional responses, along with the disease type, nature, and lymphocyte clearance (24). Therefore, the design of CAR plays an important role in the occurrence of CRS. The leading manifestations induced by CAR19 in NSG mice include marked increases in human IFNgamma, which is one of the most sensitive cytokines related to $\mathrm{T}$ cell factor activation (25). IL-10 is a marker for the proliferation of Raji cells (26), and a significant increase of IL-10 was also found in animals bearing Raji-Luc. Combined with histopathological observations, CART19 and the proliferation of immune activated cells were found in various organs and tissues, such as, lungs, liver, spleen, kidneys and brain. In addition to a more prominent curative effect, a high therapeutic dose of CAR-T therapy could incur a risk of serious immune side effects, manifesting as an increased risk of organ infection and a chronic or even fatal granulomatous reaction (27). Kalaitsidou et al. suggested that these granulomatous areas were generated by $\mathrm{CD} 11 \mathrm{~b}^{+} \mathrm{Gr}-1^{+}$myeloid-derived suppressor cells triggered by the long-term presence of CAR-T in small quantities at the local microenvironment, which was demonstrated as splenomegaly and lymphadenopathy (14). In our study, at the therapeutic dose level $\left(0.2 \times 10^{7} \mathrm{CD} 19\right.$-positive CAR-T cell per animal) of CART19, the tumor incidences of were effectively reduced and no excessive immune response was revealed. The in vivo imaging and tissue distribution data suggested that CART19 proliferated slowly in NSG mice, and the content of CART19 in peripheral blood was significantly increased compared with the Untreated group 
from 4 weeks after administration. These findings suggested that the onset of CART19 was slower, which explained its insignificant immunotoxicity. We have previously (unpublished data) detected a marked increase of mouse IL6, the core regulator of CRS (28), which might be derived from multiple sources in immunodeficient NSG mice after CAR-T administration. Thus, different cytokine profiles could be detected after the stimulation of CAR-T using diverse strategies in the future.

Currently, there is no ideal model to accurately mimic the interactions among CAR-T cells, tumor cells, normal cells, and the immune system in patients. NSG mice xenografted with NALM-6 (leukemia) or Raji (lymphoma) tumor cells are the most commonly used and internationally recognized models for evaluating the efficacy and toxicity of CAR-T targeting at CD19 (29,30). A predominant benefit of using the human xenograft mice is to immediately verify the effects of humanized CAR-T on humanized tumor cells. Another advantage of NSG mice which lack T cells, $B$ cells and NK cells and have innate immune defects, is that they show less rejection reaction and milder GvHD. In this study, CART19 showed its efficacy in improving the survival rate and symptoms induced by Raji-Luc cells, and little risk of CRS was found. Our previous clinical studies showed the advantages of CART19 therapy in patients with R/R ALL, as both the remission rate and the survival period were significantly improved $(15,16)$. This study further confirmed the prominent efficacy and safety of CART19 in animals, and provided key evidence for its clinical approval. In contrast, the potential on-target offtumor toxicities of CAR-T were hardly observed due to the deficiency of the host immune system (12). It is also impossible to observe the interaction between CAR-T cells and other immune cells or tissues in vivo by simulating the cascade reaction caused by CRS in xenograft mice. However, the proliferations of immune-activated cells in major organs was observed, indicating a risk of overloading the immune response. In addition, hepatocyte necrosis and fibrosis were also found, implying a hepatoxicity risk. These observations are difficult to acquire in clinical trials. Hence, the NSG mice could predict the CRS and other side effects to some extent, and they have also been adopted in the preclinical studies for both Yescarta and Kymriah. Many scientists are attempting to develop better animal models for evaluating their efficacy and toxicity (31), and various humanized mouse models have been used to detect the immunotoxicity and targeted nontumor toxicity of CAR-T cell products in the early development stages. However, these models have not been used in toxicity studies for the application of investigational new drugs (INDs) due to their low yield and high costs. Moreover, the US FDA still has no recommended animal models. The choice of animal models in the preclinical safety evaluation for CAR-T depends on the nature of the cells and the rational design of the study. Meanwhile, non-tumor-bearing immunodeficient mice, which allow CAR-T cells to survive for longer periods of time, are a better choice evaluating nontarget safety risks of CAR-T and its potential tumorigenicity.

In summary, our study provided a comprehensive report of the efficacy, biodistribution, toxicity, and especially the immunotoxicity, of CAR-T using an NSG and Rajicell xenograft lymphoma model. NSG mice that received CART19 treatment demonstrated a longer survival period without significant immunotoxicity, suggesting an encouraging clinical prospect for CART19 in patients with R/R ALL. More importantly, these findings shed lights on the evaluation and supervision strategies for CAR-T products for the treatment of hematological diseases or leukemia to maintain the upsurge of development of CAR-T therapy. This study is an example of performing a comprehensive preclinical safety evaluation of novel CAR-T products for regulatory review. Our research data were used for an IND application of CART19 to the National Medical Products Administration, which was granted clinical trial permission in China.

\section{Acknowledgments}

The authors gratefully acknowledge the expert technical assistance and support of Ming Li, Chao Qin, Jing Zhao, Yufa Miao, and Yanwei Yang at National Center for Safety Evaluation of Drugs, and Ailing Wang at Beijing Huatai Biotechnology Co., Ltd.

Funding: This work is supported by the "Significant New Drugs Development" (No. 2015ZX09501007-004 and 2018ZX09201-017) and National Key Research and Development Program (No. 2016YFA0101503) from the Ministry of Science and Technology of the People's Republic of China (http://www.most.gov.cn/).

\section{Footnote}

Conflicts of Interest: The authors have no conflicts of interest to declare.

Ethical Statement: The authors are accountable for all 
aspects of the work in ensuring that questions related to the accuracy or integrity of any part of the work are appropriately investigated and resolved. All animal experimental procedures were approved by the Institutional Animal Care and Use Committee (IACUC) of National Center for Safety Evaluation of Drugs (NCSED) (No. IACUC-2018-039, IACUC-2018-040).

\section{References}

1. Ronson A, Tvito A, Rowe JM. Treatment of Relapsed/ Refractory Acute Lymphoblastic Leukemia in Adults. Curr Oncol Rep 2016;18:39.

2. Morello A, Sadelain M, Adusumilli PS. MesothelinTargeted CARs: Driving T Cells to Solid Tumors. Cancer Discov 2016;6:133-46.

3. Hay KA, Turtle CJ. Chimeric Antigen Receptor (CAR) T Cells: Lessons Learned from Targeting of CD19 in B-Cell Malignancies. Drugs 2017;77:237-45.

4. Ghorashian S, Pule M, Amrolia P. CD19 chimeric antigen receptor $\mathrm{T}$ cell therapy for haematological malignancies.

Br J Haematol 2015;169:463-78.

5. Lee DW, Kochenderfer JN, Stetler-Stevenson M, et al. T cells expressing CD19 chimeric antigen receptors for acute lymphoblastic leukaemia in children and young adults: a phase 1 dose-escalation trial. Lancet 2015;385:517-28.

6. Park JH, Geyer MB, Brentjens RJ. CD19-targeted CAR T-cell therapeutics for hematologic malignancies: interpreting clinical outcomes to date. Blood 2016;127:3312-20.

7. Neelapu SS, Locke FL, Bartlett NL, et al. Axicabtagene Ciloleucel CAR T-Cell Therapy in Refractory Large B-Cell Lymphoma. N Engl J Med 2017;377:2531-44.

8. Ruella M, Kenderian SS. Next-Generation Chimeric Antigen Receptor T-Cell Therapy: Going off the Shelf. BioDrugs 2017;31:473-81.

9. Grigor EJM, Fergusson D, Kekre N, et al. Risks and Benefits of Chimeric Antigen Receptor T-Cell (CAR-T) Therapy in Cancer: A Systematic Review and MetaAnalysis. Transfus Med Rev 2019;33:98-110.

10. Gust J, Finney OC, Li D, et al. Glial injury in neurotoxicity after pediatric CD19-directed chimeric antigen receptor $\mathrm{T}$ cell therapy. Ann Neurol 2019;86:42-54.

11. Wang X, Qi Z, Wei H, et al. Characterization of human B cells in umbilical cord blood-transplanted NOD/SCID mice. Transpl Immunol 2012;26:156-62.

12. Tasian SK, Kenderian SS, Shen F, et al. Optimized depletion of chimeric antigen receptor $\mathrm{T}$ cells in murine xenograft models of human acute myeloid leukemia. Blood 2017;129:2395-407.

13. Barrett DM, Teachey DT, Grupp SA. Toxicity management for patients receiving novel T-cell engaging therapies. Curr Opin Pediatr 2014;26:43-9.

14. Kalaitsidou M, Kueberuwa G, Schutt A, et al. CAR T-cell therapy: toxicity and the relevance of preclinical models. Immunotherapy 2015;7:487-97.

15. Hu Y, Wu Z, Luo Y, et al. Potent Anti-leukemia Activities of Chimeric Antigen Receptor-Modified T Cells against CD19 in Chinese Patients with Relapsed/ Refractory Acute Lymphocytic Leukemia. Clin Cancer Res 2017;23:3297-306.

16. Wei G, Hu Y, Pu C, et al. CD19 targeted CAR-T therapy versus chemotherapy in re-induction treatment of refractory/relapsed acute lymphoblastic leukemia: results of a case-controlled study. Ann Hematol 2018;97:781-9.

17. Chu Y, Hochberg J, Yahr A, et al. Targeting CD20+ Aggressive B-cell Non-Hodgkin Lymphoma by AntiCD20 CAR mRNA-Modified Expanded Natural Killer Cells In Vitro and in NSG Mice. Cancer Immunol Res 2015;3:333-44.

18. Zhou X, Shen L, Liu L, et al. Preclinical safety evaluation of recombinant adeno-associated virus 2 vector encoding human tumor necrosis factor receptor-immunoglobulin Fc fusion gene. Hum Vaccin Immunother 2016;12:732-9.

19. Schneider D, Xiong Y, Wu D, et al. A tandem CD19/ CD20 CAR lentiviral vector drives on-target and off-target antigen modulation in leukemia cell lines. J Immunother Cancer 2017;5:42.

20. Vestergaard HT, D'Apote L, Schneider CK, et al. The evolution of nonclinical regulatory science: advanced therapy medicinal products as a paradigm. Mol Ther 2013;21:1644-8.

21. Rizzieri DA, Dev P, Long GD, et al. Response and toxicity of donor lymphocyte infusions following T-cell depleted non-myeloablative allogeneic hematopoietic SCT from 3-6/6 HLA matched donors. Bone Marrow Transplant 2009;43:327-33.

22. Chapelin F, Gao S, Okada H, et al. Fluorine-19 nuclear magnetic resonance of chimeric antigen receptor $\mathrm{T}$ cell biodistribution in murine cancer model. Sci Rep 2017;7:17748.

23. Khadka RH, Sakemura R, Kenderian SS, et al. Management of cytokine release syndrome: an update on emerging antigen-specific $\mathrm{T}$ cell engaging immunotherapies. Immunotherapy 2019;11:851-7.

24. Brudno JN, Kochenderfer JN. Recent advances in 
Page 18 of 18

CAR T-cell toxicity: Mechanisms, manifestations and management. Blood Rev 2019;34:45-55.

25. Pennell CA, Barnum JL, McDonald-Hyman CS, et al. Human CD19-Targeted Mouse T Cells Induce B Cell Aplasia and Toxicity in Human CD19 Transgenic Mice. Mol Ther 2018;26:1423-34.

26. Sharma A, Kumar M, Aich J, et al. Posttranscriptional regulation of interleukin-10 expression by hsa-miR-106a. Proc Natl Acad Sci U S A 2009;106:5761-6.

27. Cheadle EJ, Sheard V, Rothwell DG, et al. Differential role of Th1 and Th2 cytokines in autotoxicity driven by CD19specific second-generation chimeric antigen receptor $\mathrm{T}$ cells in a mouse model. J Immunol 2014;192:3654-65.

28. García Roche A, Díaz Lagares C, Élez E, et al. Cytokine

Cite this article as: Wen $\mathrm{H}, \mathrm{Qu} \mathrm{Z}$, Yan Y, Pu C, Wang C, Jiang H, Hou T, Huo Y. Preclinical safety evaluation of chimeric antigen receptor-modified T cells against CD19 in NSG mice. Ann Transl Med 2019;7(23):735. doi: 10.21037/atm.2019.12.03
Wen et al. Preclinical safety evaluation of CAR-T against CD19

release syndrome. Reviewing a new entity in the intensive care unit. Med Intensiva 2019;43:480-8.

29. Pegram HJ, Purdon TJ, van Leeuwen DG, et al. IL12-secreting CD19-targeted cord blood-derived T cells for the immunotherapy of B-cell acute lymphoblastic leukemia. Leukemia 2015;29:415-22.

30. Tsukahara T, Ohmine K, Yamamoto C, et al. CD19 targetengineered T-cells accumulate at tumor lesions in human B-cell lymphoma xenograft mouse models. Biochem Biophys Res Commun 2013;438:84-9.

31. Walsh NC, Kenney LL, Jangalwe S, et al. Humanized Mouse Models of Clinical Disease. Annu Rev Pathol 2017;12:187-215. 